\title{
The kinetics of substitution reaction of oxydiacetate and thiodiacetate copper(II) complexes with 1,10-phenanthroline and 2,2'-bipyridine
}

\author{
JOANNA PRANCZK, DAGMARA JACEWICZ*, DARIUSZ WYRZYKOWSKI, \\ ALEKSANDRA TESMAR and LECH CHMURZYŃSKI \\ Faculty of Chemistry, University of Gdańsk, Wita Stwosza 63, 80-308 Gdańsk, Poland \\ e-mail: dagmara.jacewicz@ug.edu.pl
}

MS received 6 July 2015; revised 14 August 2015; accepted 20 August 2015

\begin{abstract}
The kinetics of substitution reactions of the CuODA and CuTDA binary complexes (ODA = oxydiacetate, TDA = thiodiacetate) with 1,10-phenanthroline (phen) and 2,2'-bipyridine (bipy) were studied in aqueous and DMSO solutions. These reactions were monitored spectrometrically using the stopped-flow method in the UV range. The studies were carried out at three temperatures - 298.15, 303.15 and $308.15 \mathrm{~K}$. The concentrations of the binary complexes were kept within the range of $0.2-0.5 \mathrm{mmol} \mathrm{L}^{-1}$, whereas the concentration of phen or bipy was constant $=0.05 \mathrm{mmol} \mathrm{L}^{-1}$. The values of the reaction rate constants were calculated based on the $\mathrm{A} \rightarrow \mathrm{B}$ reaction model. A linear relationship of the rate of the substitution reaction versus the concentration of the binary complex as well as temperature was observed. The impact of the type of the primary (ODA and TDA) and auxiliary ligands (phen and bipy) as well as the effect of solvent on the rate of substitution reaction have been discussed.
\end{abstract}

Keywords. Solvents effects; copper(II) complexes; kinetics; stopped-flow method.

\section{Introduction}

The polycarboxylate ions such as oxydiacetate (ODA) and thiodiacetate (TDA) are commonly used in the coordination chemistry. ${ }^{1,2}$ The ODA ligand may adopt the planar (mer) and facial (fac) conformations (figure 1). On the other hand, the TDA ligand never adopts the mer conformation in the solid state. The polycarboxylate metal complexes have interesting spectroscopic, magnetic and structural characteristics. ${ }^{3}$ Moreover, the oxydiacetate complexes with $\mathrm{Co}^{2+}, \mathrm{Ni}^{2+}$ and $\mathrm{VO}^{2+}$ show the antioxidant properties towards superoxide free radicals. $^{4}$

The recent results of the studies of our research group show that $\mathrm{Co}^{2+}$ and $\mathrm{Ni}^{2+}$ complexes with ODA and TDA undergo a substitution reaction with phen and bipy in aqueous solutions. ${ }^{5,6}$ CoODA, CoTDA, NiODA and NiTDA binary complexes exhibit a tendency towards the substitution of two water molecules for phen or bipy molecules. For this reason it seemed to be interesting to compare the influence of the ionic coordination centers $\mathrm{Co}^{2+}$ and $\mathrm{Ni}^{2+}$ with $\mathrm{Cu}^{2+}$ ions on the substitution reaction of oxydiacetate and thiodiacetate metal complexes (CuODA and CuTDA complexes with phen and bipy as auxiliary ligands). Moreover, in this report the

\footnotetext{
*For correspondence
}

substitution reaction of $\mathrm{Cu}$ (II) oxydiactate and thiodiacetate complexes have also been investigated in DMSO solution. The physico-chemical as well as acidbase properties of non-aqueous solvents including DMSO affect coordinating properties of ligands such as pyridine derivatives and consequently it may influence the reaction kinetics in this medium. ${ }^{7-11}$ The medium of reaction (the physico-chemical and acidbase properties of solvent) may have an important impact on the rate of the reactions. So far, the kinetic stability of such complexes and the effect of solvent on the rates of formation of complexes have not been studied systematically. However, in the literature there are some reports on the influence of medium on the rate constants of substitution reactions of coordination compounds. For example, the solvent effect on the complexation reaction of oxalato pentaamminecobalt(III) with nickel(II) in methanol-water medium was investigated. ${ }^{12}$ Having in mind the differences in the physico-chemical and acid-base properties of DMSO and $\mathrm{H}_{2} \mathrm{O}$, we undertook the studies to determine the effect of the solvent on the rate of substitution reaction of complex compounds studied. It should be stressed that during the substitution reactions studied the ternary complexes are formed. Furthermore, a presence of two water molecules in the 
1.
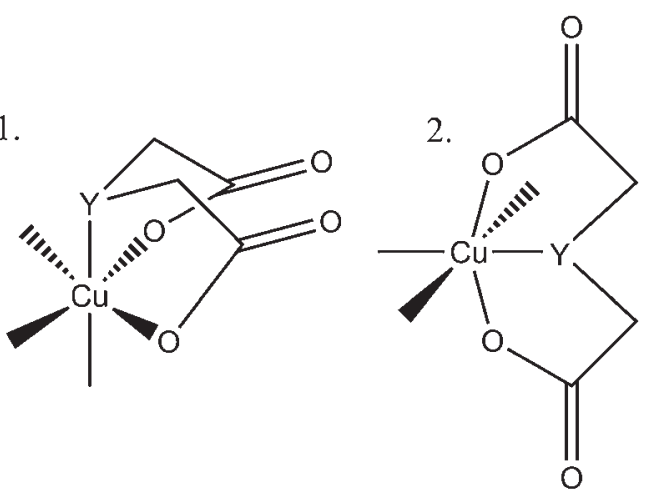

$\mathrm{Y}=\mathrm{O}$ or $\mathrm{S}$ atom

Figure 1. The conformations of the ODA and TDA ions: fac (1) and mer (2).

coordination sphere of CuODA and CuTDA allows to design new ternary complexes of desirable physicochemical properties. The investigations of $\mathrm{Cu}$ (II) polycarboxylate complexes in solutions are interesting because these complexes play important biological roles. The $\mathrm{Cu}^{2+}$ complex with iminodiacetate dianion as a primary ligand and phen as an auxiliary ligand show antimicrobial and antifungal activity. ${ }^{13}$ Moreover, the $\mathrm{Cu}$ (II) polycarboxylate complexes exhibit anticancer and antiplatelet properties. ${ }^{14,15}$

\section{Experimental}

\subsection{Synthesis of the complexes}

The series of complexes, $[\mathrm{Cu}(\mathrm{ODA})] \leq 0.5 \mathrm{H}_{2} \mathrm{O}(\mathrm{CuODA})$, $[\mathrm{Cu}(\mathrm{ODA})$ phen $] \leq 3 \mathrm{H}_{2} \mathrm{O}$ (CuODAphen),

$\left[\mathrm{Cu}(\mathrm{ODA})\right.$ bipy $\left.\left(\mathrm{H}_{2} \mathrm{O}\right)\right] \leq 4 \mathrm{H}_{2} \mathrm{O}(\mathrm{CuODAbipy}),[\mathrm{Cu}(\mathrm{TDA})]_{\mathrm{n}}$ (CuTDA), [Cu(TDA)phen $]_{2} \leq \mathrm{H}_{2}$ TDA (CuTDAphen), $\left[\mathrm{Cu}(\mathrm{TDA})\right.$ bipy $\left.\left(\mathrm{H}_{2} \mathrm{O}\right)\right] \leq 4 \mathrm{H}_{2} \mathrm{O}$ and (CuTDAbipy) were synthesized by known methods described in the literature. ${ }^{16-21}$ Elemental analyses of the polycar boxylate complexes were performed with the Vario EL analyzer Cube CHNS. Anal. Calcd. for $[\mathrm{Cu}(\mathrm{ODA})] \cdot 0.5 \mathrm{H}_{2} \mathrm{O}: \mathrm{C}, 23.47 \%, \mathrm{H}, 2.44 \%$. Found: C, $23.11 \%, \mathrm{H}, 2.16 \%$. Anal. Calcd for [Cu(ODA)phen]. $3 \mathrm{H}_{2} \mathrm{O}: \mathrm{C}, 44.68 \%, \mathrm{H}, 4.19 \%, \mathrm{~N}, 6.52 \%$. Found: C, $43.95 \%, \mathrm{H}, 3.78 \%, \mathrm{~N}, 6.88 \%$. Anal. Calcd for $[\mathrm{Cu}$ (ODA)bipy $\left.\left(\mathrm{H}_{2} \mathrm{O}\right)\right] \cdot 4 \mathrm{H}_{2} \mathrm{O}: \mathrm{C}, 38.05 \%, \mathrm{H}, 4.98 \%, \mathrm{~N}$, 6.34\%. Found: $\mathrm{C}, 37.76 \%, \mathrm{H}, 4.79 \%, \mathrm{~N}, 6.15 \%$. Anal. Calcd for $[\mathrm{Cu}(\mathrm{TDA})]_{\mathrm{n}}: \mathrm{C}, 22.69 \%, \mathrm{H}, 1.89 \%, \mathrm{~S}$, $15.13 \%$. Found: C, $22.45 \%, \mathrm{H}, 1.43 \%, \mathrm{~S}, 14.79 \%$. Anal. Calcd for $[\mathrm{Cu}(\mathrm{TDA}) \mathrm{phen}]_{2} \cdot \mathrm{H}_{2} \mathrm{TDA}: \mathrm{C}, 46.28 \%$, H, $3.21 \%$, N, $6.0 \%$, S, $10.28 \%$. Found: C, $46.10 \%$, H, $3.04 \%, \mathrm{~N}, 5.94 \%, \mathrm{~S}, 10,11 \%$. Anal. Calcd for $[\mathrm{Cu}$ (TDA)bipy $\left.\left(\mathrm{H}_{2} \mathrm{O}\right)\right] \cdot 4 \mathrm{H}_{2} \mathrm{O}: \mathrm{C}, 36.72 \%, \mathrm{H}, 4.81 \%, \mathrm{~N}$,
$6.12 \%$, S, 6.99\%. Found: C, 36.32\%, H, 4.79\%, N, $5.88 \%, \mathrm{~S}, 6.53 \%$.

\subsection{Instrumentation}

UV spectra were recorded using the Perkin-Elmer Lambda 650 instrument equipped with the temperature control - Peltier system with a scan accuracy of $1 \mathrm{~nm}$ and a $1 \mathrm{~nm}$ slit width at a scanning rate $120 \mathrm{~nm} \mathrm{~min}^{-1}$. The progress of the substitution reaction of $\left[\mathrm{Cu}(\mathrm{R})(\mathrm{S})_{\mathrm{n}}\right]$ ( $\mathrm{R}=$ ODA or TDA, $\mathrm{S}=\mathrm{H}_{2} \mathrm{O}$ or DMSO) with bipy or phen ligands was monitored using the Applied Photophysics SX-17MV spectrophotometer.

\subsection{Kinetic measurements}

The substitution reactions of phen or bipy for the aqua or DMSO ligand in the CuODA and CuTDA coordination compounds were monitored spectrophotometrically using the stopped-flow method. The values of observable rate constants were calculated using the "Glint" program based on the global analysis. ${ }^{22,23}$ The concentrations of the binary complex were within the range of $0.2-0.5 \mathrm{mmol} \mathrm{L}^{-1}$, whereas the concentration of phen or bipy was kept constant at $0.05 \mathrm{mmol} \mathrm{L}^{-1}$. The kinetics of substitution reactions of CuODA and CuTDA complexes were monitored in the UV range. The changes of absorbance were observed in DMSO at $278 \mathrm{~nm}$ for CuODAbipy, at $258 \mathrm{~nm}$ for CuODAphen, at $306 \mathrm{~nm}$ for CuTDAbipy, at $280 \mathrm{~nm}$ for CuTDAphen and in $\mathrm{H}_{2} \mathrm{O}$ at $314 \mathrm{~nm}$ for CuODAbipy, at $260 \mathrm{~nm}$ for $\mathrm{CuO}$ DAphen, at $255 \mathrm{~nm}$ for CuTDAbipy and at $230 \mathrm{~nm}$ for CuTDAphen.

\section{Results and Discussion}

In aqueous or DMSO solution, the two solvent molecules in the coordination sphere of $\mathrm{Cu}$ (II) are substituted by phen or bipy (equation 1).

$$
\left[\mathrm{Cu}(\mathrm{R})(\mathrm{S})_{3}\right]+\mathrm{B} \rightarrow 2 \mathrm{~S}+[\mathrm{Cu}(\mathrm{R})(\mathrm{B}) \mathrm{S}]
$$

$\mathrm{R}=\mathrm{ODA}$ or TDA, $\mathrm{B}=$ phen or bipy, $\mathrm{S}=\mathrm{H}_{2} \mathrm{O}$ or DMSO. During the CuODA or CuTDA reaction with bipy or phen in DMSO or aqueous solutions the transition state is formed (figure 2).

All the studied complexes in aqueous and DMSO solutions are hexacoordinate. The UV spectra were recorded to select a wavelength for kinetic measurements. Spectra of the mixture of $\mathrm{B}$ and $\mathrm{CuR}$ in the molar ratio $1: 1$ and the ternary complex $\mathrm{Cu}(\mathrm{R}) \mathrm{B}$ were recorded to confirm that after mixing of the reagent 
solutions the ternary complex of known composition is formed (figures 3 and 4). In the case of the spectra recorded in aqueous solutions the bathochromic shift was observed.

Based on the kinetic equation for first-order reaction, the values of the rate constants were determined.
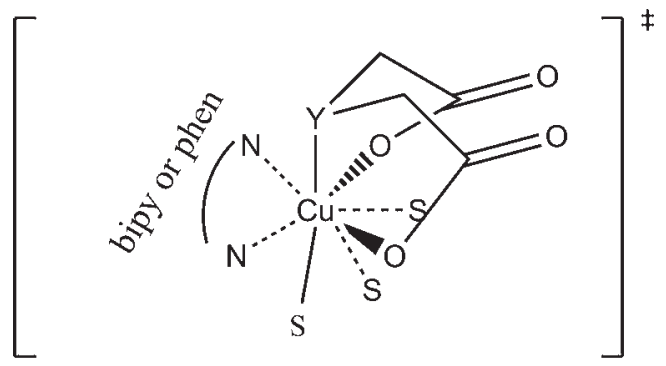

$$
\begin{aligned}
& \mathrm{S}=\mathrm{H}_{2} \mathrm{O} \text { or DMSO } \\
& \mathrm{Y}=\mathrm{O} \text { or } \mathrm{S} \text { atom }
\end{aligned}
$$

Figure 2. The suggested structure of the transition state of the reactions studied.

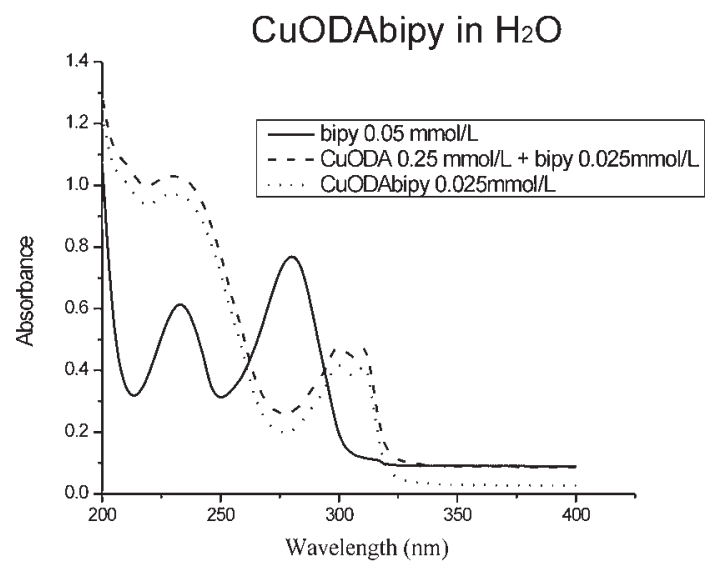

(a)

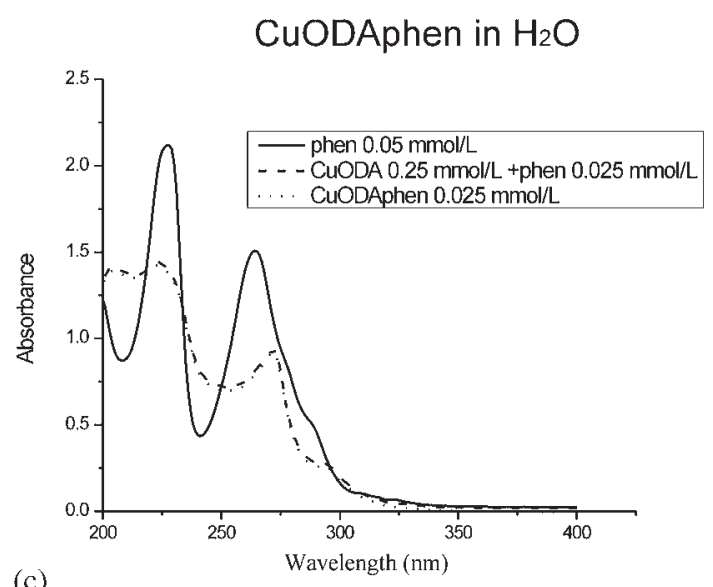

Their values were calculated based on the $\mathrm{A} \rightarrow \mathrm{B}$ reaction model. The linear relationship of the values of the observable reaction rate constants versus the concentration of the $\left[\mathrm{Cu}(\mathrm{R})(\mathrm{S})_{3}\right]$ complex as well as temperature was observed (figures 5 and 6). The interesting observation is that the substitution reaction for CuODAbipy, CuODAphen and CuTDAbipy complexes was faster in aqueous solution than in DMSO. Only in the case of CuTDAphen complex the substitution reaction in aqueous solution was slower than that in DMSO. Both solvents (DMSO and $\mathrm{H}_{2} \mathrm{O}$ ) have similar density, but DMSO has about 2 times higher viscosity than $\mathrm{H}_{2} \mathrm{O}$. A relative permittivity at $298.15 \mathrm{~K}$ for DMSO is about 2 times smaller than that of $\mathrm{H}_{2} \mathrm{O}$ (The relative permittivity in $298.15 \mathrm{~K}$ for DMSO, $\varepsilon_{\mathrm{r}}=49$ and for $\mathrm{H}_{2} \mathrm{O}$, $\left.\varepsilon_{\mathrm{r}}=78\right) .{ }^{24}$ In aqueous solutions the substitution reactions are faster than the reactions in DMSO solutions and the dielectric constant of $\mathrm{H}_{2} \mathrm{O}$ is higher than that of DMSO. This leads to the interesting observation that the solvation of the substrates (the studied complexes as well as phen or bipy) is weaker in aqueous solutions than in the DMSO solution. The solvation and viscosity

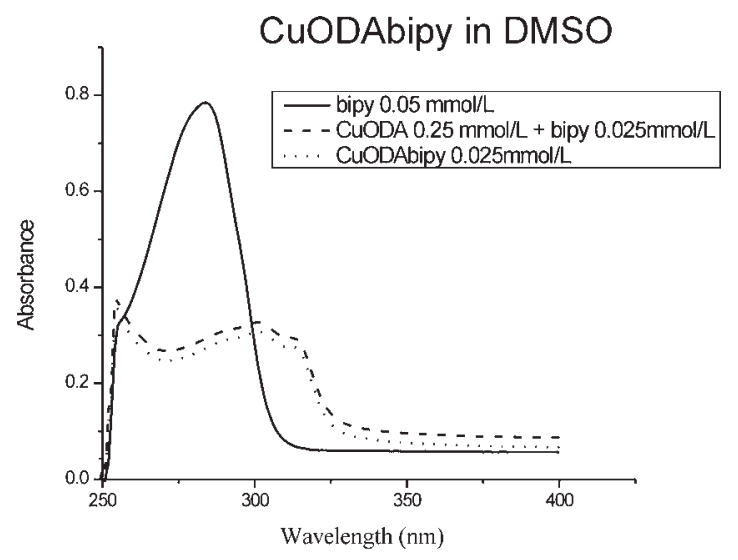

(b)

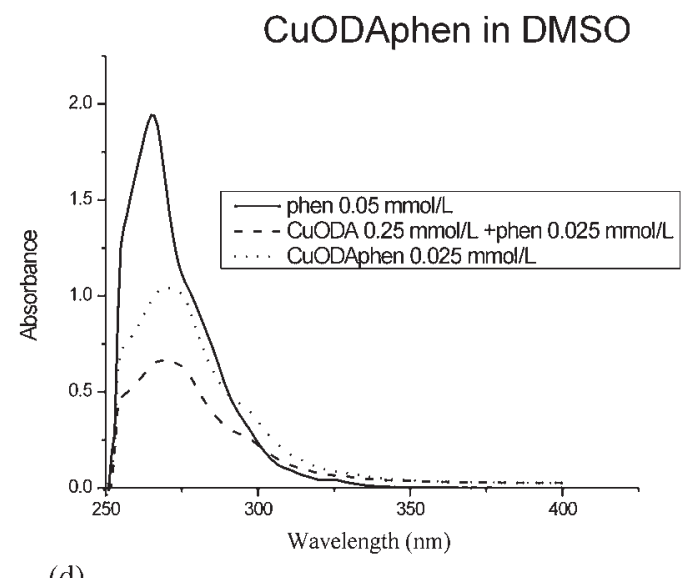

(d)

Figure 3. UV spectra of the substrate bipy or phen, the mixture of bipy or phen and CuODA in the molar ratio $1: 1$ and the ternary complex $\mathrm{Cu}(\mathrm{ODA}) \mathrm{B}$ in aqueous and DMSO solutions $(\mathrm{T}=298.15 \mathrm{~K})$. 


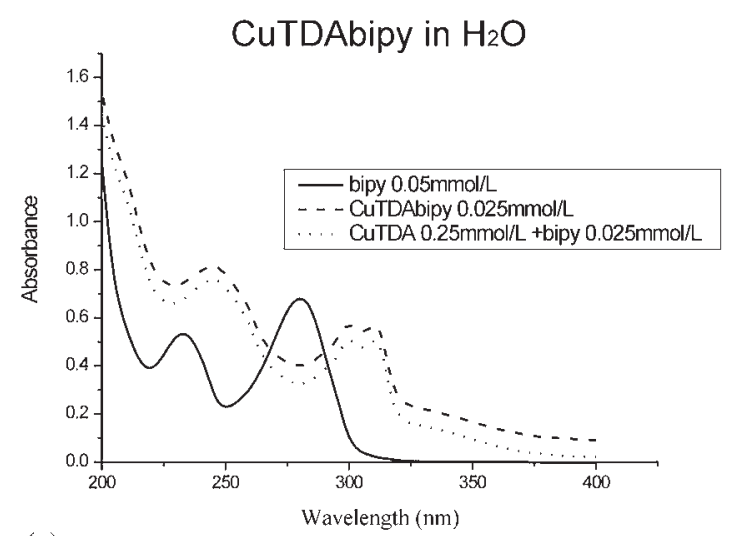

(a)

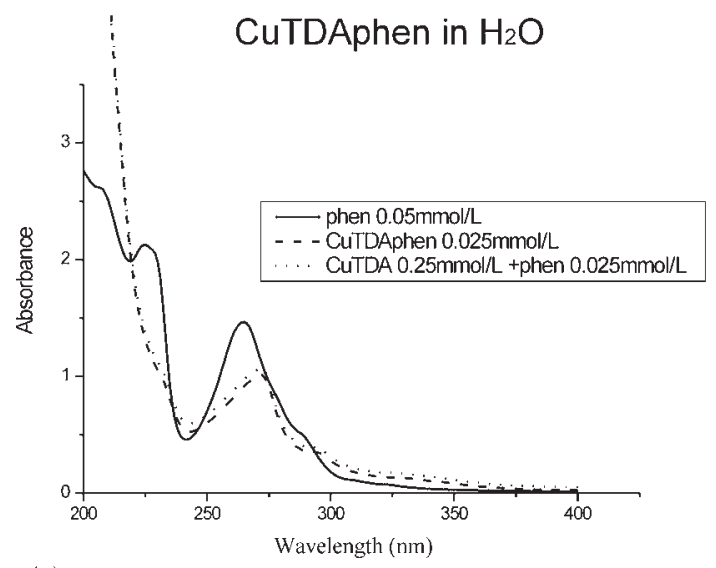

(c)

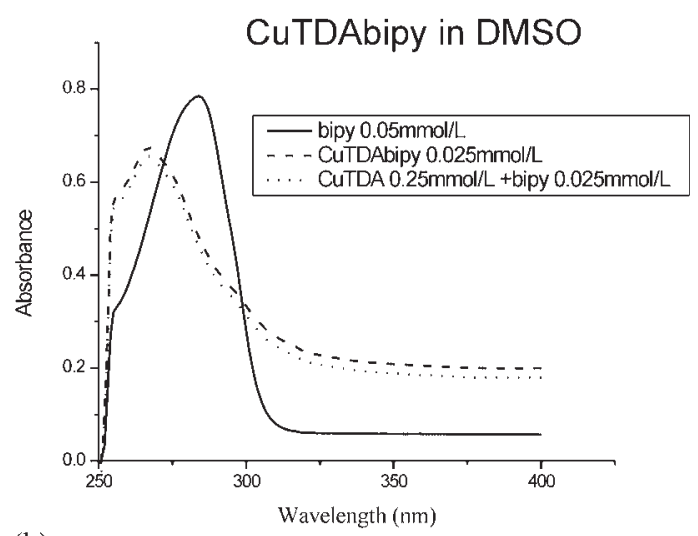

(b)

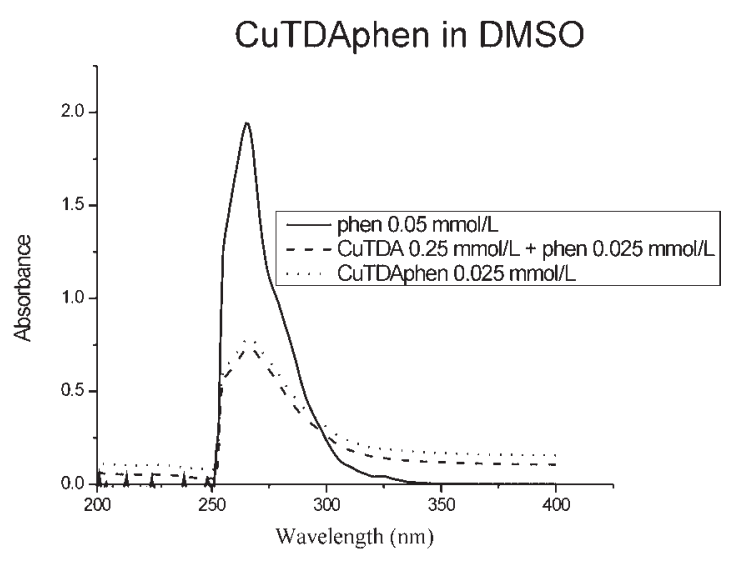

(d)

Figure 4. UV spectra of the substrate bipy or phen, the mixture of bipy or phen and CuTDA in the molar ratio $1: 1$ and the ternary complex $\mathrm{Cu}(\mathrm{TDA}) \mathrm{B}$ in aqueous and DMSO solutions $(\mathrm{T}=298.15 \mathrm{~K})$.

are the main factors determining the rate of these substitution reactions. Moreover, the substitution reactions in all cases of the binary complexes were faster with bipy than the reactions with phen in aqueous and DMSO solutions. It can be explained by the fact that phen is more basic than bipy. Probably the interaction between two ligands (polycarboxylate anion and bipy or phen) in the coordination sphere of $\mathrm{Cu}$ (II) promotes the coordination of bipy. Analyzing the impact of the primary ligand on the reaction rate constants, it can be seen that the complexes containing TDA ligand in almost all cases are faster in the substitution of ligands in the coordination sphere of $\mathrm{Cu}$ (II) than similar complexes with ODA ligand. In contrast to the ODA ligand, the TDA ligand never adopts a planar conformation in the coordination sphere of the metal ion. ${ }^{25}$ This is due to an elongation of the bond between the sulfur atom and the metal ion. The ODA ligand may adopts fac and mer conformation in CuODA, but the TDA ligand adopts only the $f a c$ conformation in the CuTDA binary complex. This fact may be the reason for differences in the rate of the substitution reaction of the studied complexes.
Further, activation parameters for all the substitution reactions studied were calculated based on the Eyring equation (tables 1-6). ${ }^{26,27}$ In the case of the substitution reaction of CuTDA with phen, the results obtained using on Eyring equation were unrepeatable and were not compatible with the Eyring plot. In aqueous solutions higher decrease of $\Delta S^{\#}$ was observed than in case of DMSO. This means that $\mathrm{H}_{2} \mathrm{O}$ solvates less the active complex than DMSO. The changes in $\Delta \mathrm{H}^{\#}$ and $\Delta S^{\#}$ partially compensate each other. A less negative value of entropy in DMSO may suggest higher tendency of solvation of the active complex by DMSO molecules than by water molecules.

As can be seen from the tables, activation parameters as quoted are sensitive to the concentrations of the $\mathrm{Cu}$ (II) complexes. This inconsistency can be explained by the fact that these parameters were calculated for three temperatures only. Thus, probably due to the insufficient number of measurement points the fitting $\mathrm{y}=\mathrm{f}(\mathrm{x})$ in all cases has not been satisfactory. For this reason, in some cases the determined value has varied depending on the concentration of the reactants. The limited number of temperatures studied 


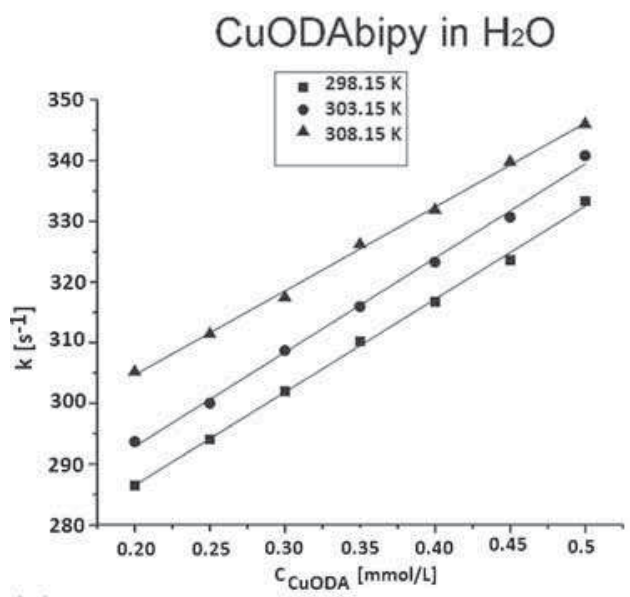

(a)

\section{CuODAphen in $\mathrm{H}_{2} \mathrm{O}$}

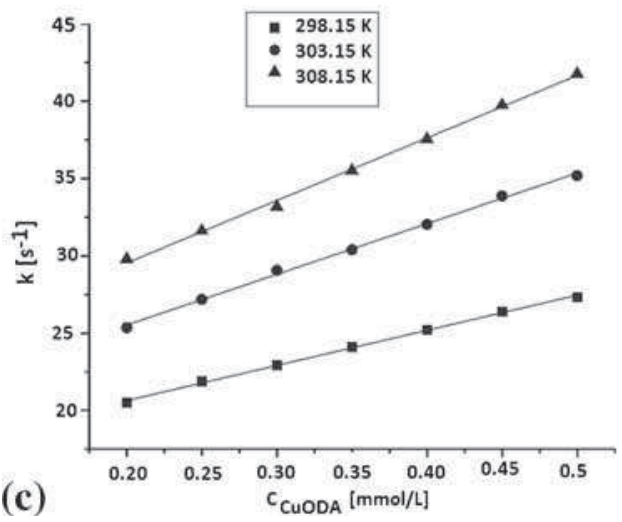

CuODAbipy in DMSO

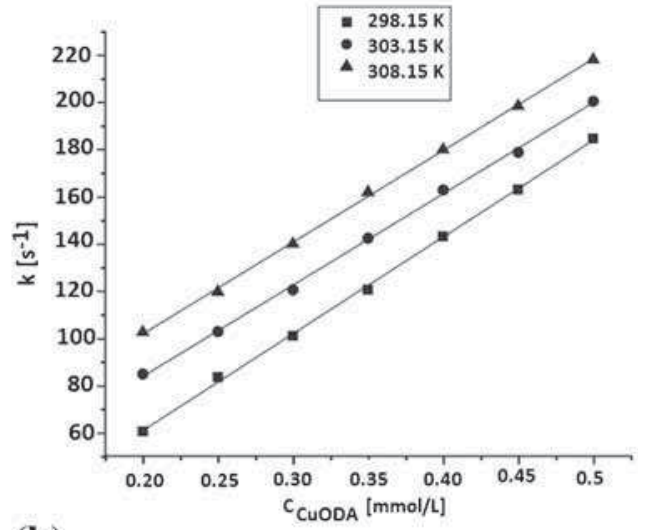

(b)

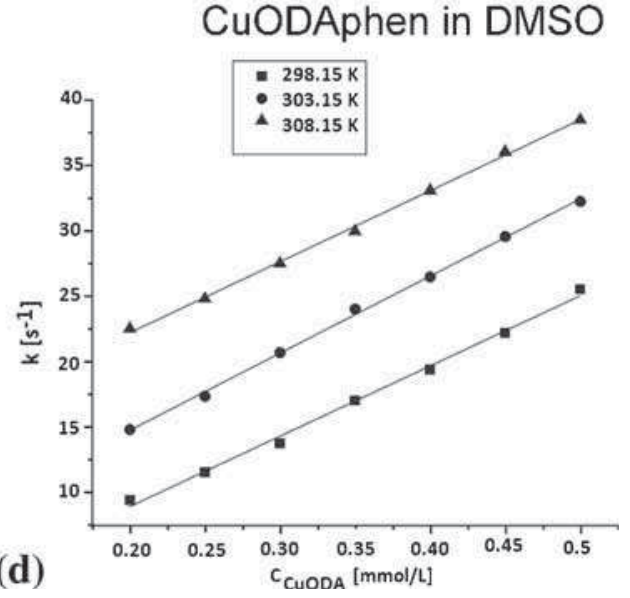

Figure 5. The dependence of the observed rate constants $k_{o b s}$ for the substitution reaction at three temperatures as a function of CuODA concentration.

is a result of physico-chemical properties of DMSO. At temperatures lower than $20^{\circ} \mathrm{C}$, DMSO solutions freeze and at temperatures higher than $35^{\circ} \mathrm{C}$, the results obtained are not repeatable.

Based on the results of the kinetic studies on substitution reactions described in this report and results of the kinetic measurements described in the literature ${ }^{28}$ concerning cobalt(II) and nickel(II) oxydiacetate and thiodiacetate complexes, it can be noted that in aqueous solutions the substitution reactions are the fastest for the $\mathrm{Cu}(\mathrm{II})\left(\mathrm{t}_{2 \mathrm{~g}}{ }^{6} \mathrm{e}_{\mathrm{g}}{ }^{3}\right)$ complexes and the slowest for $\mathrm{Ni}(\mathrm{II})$ complexes. In the case of thiodiacetate complexes, the substitution reaction is faster for $\mathrm{Co}(\mathrm{II})$ $\left(\mathrm{t}_{2 \mathrm{~g}}{ }^{5} \mathrm{e}_{\mathrm{g}}^{2}\right)$ than for the $\mathrm{Ni}(\mathrm{II})\left(\mathrm{t}_{2 \mathrm{~g}}{ }^{6} \mathrm{e}_{\mathrm{g}}{ }^{2}\right)$ complexes. ${ }^{28}$ It may result from the fact that $\mathrm{Co}$ (II) causes ODA ligand to assume the mer conformation in solutions more easily than $\mathrm{Ni}$ (II). Moreover, during the substitution reactions ternary complexes of $\mathrm{Co}$ (II) are formed with the ODA ligands adopting the fac conformation. This conformation is more advantageous than mer conformation.

\section{Conclusions}

The substitution reactions of CuODA and CuTDA binary complexes are about two times faster in $\mathrm{H}_{2} \mathrm{O}$ than in DMSO. An exception is the reaction the binary complex CuTDA with phen. The $\Delta S^{\#}$ is less negative in DMSO solutions as compared with the aqueous solutions and this means that the solvation of the active complex by water molecules is weaker than DMSO solvation. Differences in the substitution reaction rate constants may be due to different geometrical conformational (fac/mer) of the ODA and TDA primary ligands. Taking the results of the studies into account it can be concluded that the solvation and viscosity are the main factors determining the rate of substitution reactions of the binary complexes. The substitution reaction is slower at higher viscosity. Further, based on the results of the studies it can be concluded that weaker solvation of the complexes increases the rate of substitution reaction. 


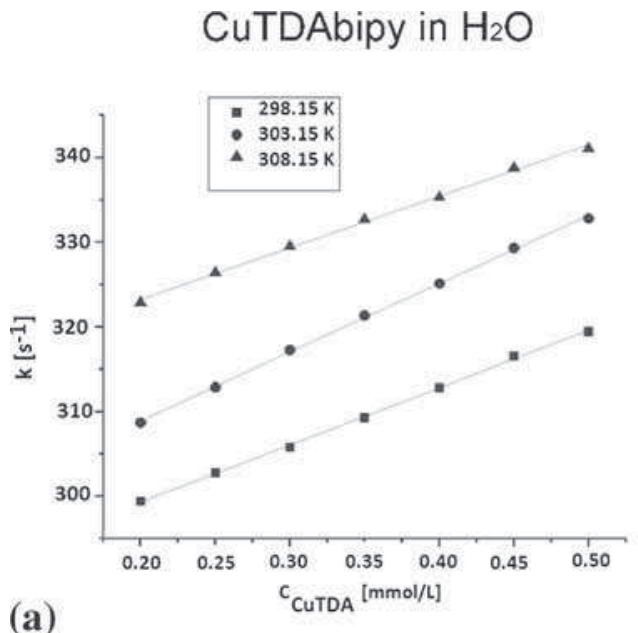

(a)

\section{CuTDAphen in $\mathrm{H}_{2} \mathrm{O}$}

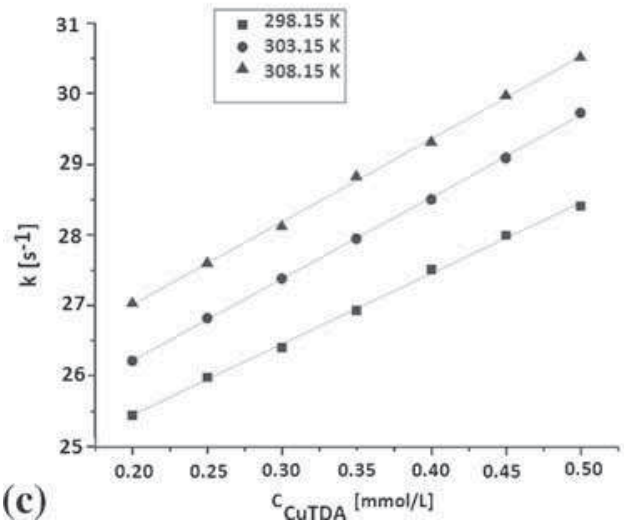

CuTDAbipy in DMSO

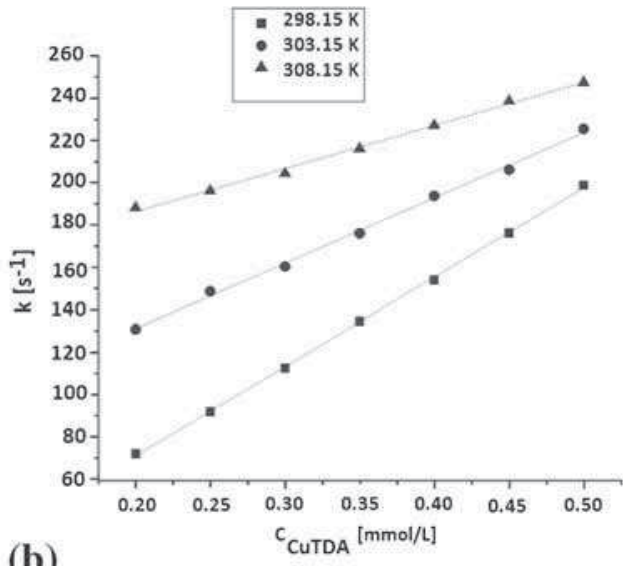

(b)

\section{CuTDAphen in DMSO}

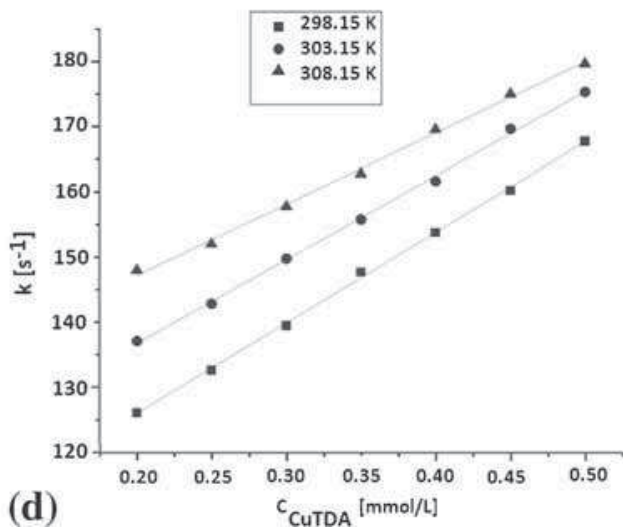

Figure 6. The dependence of the observed rate constants $k_{o b s}$ for the substitution reaction at three temperatures as a function of CuTDA concentration.

Table 1. Activation parameters with standard deviations for the substitution reaction of CuODA with bipy.

\begin{tabular}{lcrrr}
\hline Concentration of & \multicolumn{2}{c}{$\Delta \mathrm{H}^{\#}[\mathrm{~kJ} / \mathrm{mol}]$} & \multicolumn{2}{c}{$\Delta \mathrm{S}^{\#}[\mathrm{~J} / \mathrm{mol} \cdot \mathrm{K}]$} \\
\cline { 2 - 3 } CuODA [mmol/L] & $\mathrm{H}_{2} \mathrm{O}$ & $\mathrm{DMSO}$ & & $\mathrm{H}_{2} \mathrm{O}$ \\
$\mathbf{0 . 5 0}$ & $0.3 \pm 0.3$ & $13.5 \pm 2.3$ & $-195.5 \pm 1.0$ & DMSO \\
$\mathbf{0 . 4 5}$ & $1.2 \pm 0.3$ & $12.5 \pm 0.6$ & $-192.9 \pm 0.9$ & $-156.2 \pm 7.4$ \\
$\mathbf{0 . 4 0}$ & $1.1 \pm 0.3$ & $14.9 \pm 1.1$ & $-193.5 \pm 1.0$ & $-153.6 \pm 2.0$ \\
$\mathbf{0 . 3 5}$ & $1.3 \pm 0.6$ & $19.9 \pm 1.5$ & $-192.9 \pm 2.1$ & $-138.3 \pm 4.9$ \\
$\mathbf{0 . 3 0}$ & $1.3 \pm 0.3$ & $22.3 \pm 0.9$ & $-193.1 \pm 0.9$ & $-131.8 \pm 3.0$ \\
$\mathbf{0 . 2 5}$ & $1.8 \pm 0.8$ & $25.1 \pm 2.2$ & $-191.5 \pm 2.7$ & $-124.1 \pm 7.3$ \\
$\mathbf{0 . 2 0}$ & $2.3 \pm 0.6$ & $37.7 \pm 6.1$ & $-190.1 \pm 2.1$ & $-84.0 \pm 20.0$ \\
\hline
\end{tabular}

Table 2. Activation parameters with standard deviations for the substitution reaction of CuODA with phen.

\begin{tabular}{lcrcr}
\hline Concentration of & \multicolumn{2}{c}{$\Delta \mathrm{H}^{\#}[\mathrm{~kJ} / \mathrm{mol}]$} & \multicolumn{2}{c}{$\Delta \mathrm{S}^{\#}[\mathrm{~J} / \mathrm{mol} \cdot \mathrm{K}]$} \\
\cline { 2 - 5 } CuODA [mmol/L] & \multicolumn{1}{c}{$\mathrm{H}_{2} \mathrm{O}$} & $\mathrm{DMSO}$ & $\mathrm{H}_{2} \mathrm{O}$ & $\mathrm{DMSO}$ \\
\hline $\mathbf{0 . 5 0}$ & $30.0 \pm 3.3$ & $28.9 \pm 2.2$ & $-195.5 \pm 1.0$ & $-116.8 \pm 12.8$ \\
$\mathbf{0 . 4 5}$ & $28.8 \pm 3.7$ & $34.7 \pm 3.6$ & $-192.8 \pm 0.9$ & $-121.0 \pm 12.1$ \\
$\mathbf{0 . 4 0}$ & $28.0 \pm 3.3$ & $38.4 \pm 3.5$ & $-193.5 \pm 1.0$ & $-124.2 \pm 10.7$ \\
$\mathbf{0 . 3 5}$ & $27.2 \pm 3.1$ & $40.6 \pm 4.9$ & $-192.9 \pm 2.1$ & $-127.3 \pm 10.2$ \\
$\mathbf{0 . 3 0}$ & $25.8 \pm 4.4$ & $50.5 \pm 5.0$ & $-193.1 \pm 0.9$ & $-132.3 \pm 14.4$ \\
$\mathbf{0 . 2 5}$ & $25.6 \pm 2.7$ & $55.9 \pm 1.6$ & $-191.5 \pm 2.7$ & $-133.2 \pm 8.8$ \\
$\mathbf{0 . 2 0}$ & $26.1 \pm 2.0$ & $64.1 \pm 0.9$ & $-190.1 \pm 2.1$ & $-132.2 \pm 6.7$ \\
\hline
\end{tabular}


Table 3. Activation parameters with standard deviations for the substitution reaction of CuTDA with bipy.

\begin{tabular}{lrrrr}
\hline \multirow{2}{*}{$\begin{array}{l}\text { Concentration of } \\
\text { CuTDA [mmol/L] }\end{array}$} & \multicolumn{2}{c}{$\Delta \mathrm{H}^{\#}[\mathrm{~kJ} / \mathrm{mol}]$} & \multicolumn{2}{c}{$\Delta \mathrm{S}^{\#}[\mathrm{~J} / \mathrm{mol} \cdot \mathrm{K}]$} \\
\cline { 2 - 3 } $\mathbf{0 . 5 0}$ & $\mathrm{H}_{2} \mathrm{O}$ & $\mathrm{DMSO}$ & $\mathrm{H}_{2} \mathrm{O}$ & $\mathrm{DMSO}$ \\
$\mathbf{0 . 4 5}$ & $2.5 \pm 0.7$ & $14.2 \pm 1.3$ & $-188.5 \pm 2.2$ & $-153.2 \pm 4.41$ \\
$\mathbf{0 . 4 0}$ & $2.7 \pm 0.5$ & $20.7 \pm 0.3$ & $-188.1 \pm 1.5$ & $-132.5 \pm 0.91$ \\
$\mathbf{0 . 3 5}$ & $2.8 \pm 0.3$ & $27.3 \pm 2.9$ & $-187.8 \pm 1.0$ & $-111.4 \pm 9.6$ \\
$\mathbf{0 . 3 0}$ & $3.1 \pm 0.1$ & $33.7 \pm 2.4$ & $-187.0 \pm 0.3$ & $-91.0 \pm 8.1$ \\
$\mathbf{0 . 2 5}$ & $3.2 \pm 0.1$ & $43.1 \pm 4.4$ & $-186.7 \pm 0.3$ & $-61.0 \pm 14.7$ \\
$\mathbf{0 . 2 0}$ & $3.2 \pm 0.5$ & $55.5 \pm 8.5$ & $-186.6 \pm 1.5$ & $-20.8 \pm 28.0$ \\
\hline
\end{tabular}

Table 4. The free enthalpy of activation values for the substitution reaction of CuODA with bipy.

\begin{tabular}{|c|c|c|c|c|c|c|}
\hline \multirow{3}{*}{$\begin{array}{l}\text { Concentration of } \\
\mathrm{CuODA} \\
{[\mathrm{mmol} / \mathrm{L}]}\end{array}$} & \multicolumn{6}{|c|}{$\Delta \mathrm{G}^{\#}[\mathrm{~kJ} / \mathrm{mol}]$} \\
\hline & \multicolumn{2}{|c|}{$298 \mathrm{~K}$} & \multicolumn{2}{|c|}{$303 \mathrm{~K}$} & \multicolumn{2}{|c|}{$308 \mathrm{~K}$} \\
\hline & $\mathrm{H}_{2} \mathrm{O}$ & DMSO & $\mathrm{H}_{2} \mathrm{O}$ & DMSO & $\mathrm{H}_{2} \mathrm{O}$ & DMSO \\
\hline 0.50 & 58.56 & 60.05 & 59.54 & 60.83 & 60.51 & 61.61 \\
\hline 0.45 & 58.68 & 60.36 & 59.65 & 61.16 & 60.61 & 61.96 \\
\hline 0.40 & 58.76 & 60.67 & 59.73 & 61.44 & 60.70 & 62.21 \\
\hline 0.35 & 58.78 & 61.11 & 59.75 & 61.80 & 60.71 & 62.50 \\
\hline 0.30 & 58.84 & 61.58 & 59.81 & 62.24 & 60.77 & 62.89 \\
\hline 0.25 & 58.87 & 62.08 & 59.82 & 62.70 & 60.78 & 63.32 \\
\hline 0.20 & 58.95 & 62.73 & 59.90 & 63.15 & 60.85 & 63.57 \\
\hline
\end{tabular}

Table 5. The free enthalpy of activation values for the substitution reaction of CuODA with phen.

\begin{tabular}{|c|c|c|c|c|c|c|}
\hline \multirow{3}{*}{$\begin{array}{l}\text { Concentration } \\
\text { of CuODA } \\
{[\mathrm{mmol} / \mathrm{L}]}\end{array}$} & \multicolumn{6}{|c|}{$\Delta \mathrm{G}^{\#}[\mathrm{~kJ} / \mathrm{mol}]$} \\
\hline & \multicolumn{2}{|c|}{$298 \mathrm{~K}$} & \multicolumn{2}{|c|}{$303 \mathrm{~K}$} & \multicolumn{2}{|c|}{$308 \mathrm{~K}$} \\
\hline & $\mathrm{H}_{2} \mathrm{O}$ & DMSO & $\mathrm{H}_{2} \mathrm{O}$ & DMSO & $\mathrm{H}_{2} \mathrm{O}$ & DMSO \\
\hline 0.50 & 88.26 & 63.71 & 89.24 & 64.29 & 90.21 & 64.87 \\
\hline 0.45 & 86.25 & 70.76 & 87.22 & 71.36 & 88.18 & 71.97 \\
\hline 0.40 & 85.66 & 75.41 & 86.63 & 76.03 & 87.60 & 76.65 \\
\hline 0.35 & 84.68 & 78.54 & 85.65 & 79.17 & 86.61 & 79.81 \\
\hline 0.30 & 83.34 & 89.93 & 84.31 & 90.59 & 85.27 & 91.25 \\
\hline 0.25 & 82.67 & 95.59 & 83.62 & 96.26 & 84.58 & 96.93 \\
\hline 0.20 & 82.75 & 103.50 & 83.70 & 104.16 & 84.65 & 104.82 \\
\hline
\end{tabular}

Table 6. The free enthalpy of activation values for the substitution reaction of CuTDA with bipy.

\begin{tabular}{|c|c|c|c|c|c|c|}
\hline \multirow{3}{*}{$\begin{array}{l}\text { Concentration } \\
\text { of CuTDA } \\
{[\mathrm{mmol} / \mathrm{L}]}\end{array}$} & \multicolumn{6}{|c|}{$\Delta \mathrm{G}^{\#}[\mathrm{~kJ} / \mathrm{mol}]$} \\
\hline & \multicolumn{2}{|c|}{$298 \mathrm{~K}$} & \multicolumn{2}{|c|}{$303 \mathrm{~K}$} & \multicolumn{2}{|c|}{$308 \mathrm{~K}$} \\
\hline & $\mathrm{H}_{2} \mathrm{O}$ & DMSO & $\mathrm{H}_{2} \mathrm{O}$ & DMSO & $\mathrm{H}_{2} \mathrm{O}$ & DMSO \\
\hline 0.50 & 58.67 & 59.85 & 59.62 & 60.62 & 60.56 & 61.39 \\
\hline 0.45 & 58.75 & 60.19 & 59.69 & 60.85 & 60.63 & 61.51 \\
\hline 0.40 & 58.76 & 60.50 & 59.70 & 61.05 & 60.64 & 61.61 \\
\hline 0.35 & 58.83 & 60.82 & 59.76 & 61.27 & 60.70 & 61.73 \\
\hline 0.30 & 58.84 & 61.28 & 59.77 & 61.58 & 60.70 & 61.89 \\
\hline 0.25 & 58.81 & 61.70 & 59.74 & 61.80 & 60.67 & 61.91 \\
\hline 0.20 & 58.84 & 62.33 & 59.77 & 62.18 & 60.70 & 62.04 \\
\hline
\end{tabular}




\section{Supplementary Information}

The electronic supporting information can be seen at www.ias.ac.in/chemsci.

\section{Acknowledgments}

This research was supported by the National Science Centre (Grant 2011/03/D/ST5/05920).

\section{References}

1. Grirrane A, Pastor A, Alvarez E, Mealli C, Ienco A, Masi D and Galindo A 2005 Inorg. Chem. Comm. 8463

2. Hatfield W E, Helms J H, Rohrs B R, Singh P, Wasson J $\mathrm{R}$ and Weller R R 1987 Proc. Indian. Acad. Sci. Chem. Sci. 9823

3. Pavlishchuk A V, Kolotilov S V, Zeller M, Thompson L $\mathrm{K}$ and Addison A W 2014 Inorg. Chem. 531320

4. Wyrzykowski D, Inkielewicz-Stępniak I, Czupryniak J, Jacewicz D, Ossowski T, Woźniak M and Chmurzyński L 2013 Z. Anorg. Allg. Chem. 6391795

5. Wyrzykowski D, Pranczk J, Jacewicz D, Tesmar A, Pilarski B and Chmurzyński L 2014 Cent. Eur. J. Chem. 12107

6. Wyrzykowski D, Pranczk J, Jacewicz D, Tesmar A, Pilarski B and Chmurzyński L 2015 Open Chem. 13369

7. Chmurzyński L 1996 Anal. Chim. Acta. 321237

8. Chmurzyński L, Nesterowicz M, Wawrzyniak G, Kaczmarczyk E and Warnke Z 1996 Aust. J. Chem. 49 931

9. Chmurzyński L and Warnke Z 1993 Aust. J. Chem. 46 185

10. Wawrzynów A and Chmurzyński L 1998 J. Chem. Thermodyn. $\mathbf{3 0} 713$
11. Makowski M, Sadowski R, Augustin-Nowacka D and Chmurzyński L 2001 J. Phys. Chem. A 1056743

12. Dash A C and Pradhan J 1992 Int. J. Chem. Kinet. 24 155

13. Siddiqi Z A, Shahid M, Khalid M and Kumar S 2009 Eur. J. Med. Chem. 442517

14. Joseph B, Darro F, Behard A, Lesur B, Collignon F, Decaestecker C, Frydman A, Guillaumet G and Kiss R 2002 J. Med. Chem. 452534

15. Nishi T, Kimura Y and Nakagawa K 2000 Yaku-gaku. Zasshi 1201247

16. Sigel H 1980 Inorg. Chem. 191411

17. Whitlow S H and Davey G 1975 J. Chem. Soc. Dalton Trans. 1228

18. Baggio R, Calvo R, Garland M T, Pena O, Perec M and Slep L D 2007 Inorg. Chem. Commun. 101249

19. Bonomo R P, Rizzarelli E, Bresciani Pahor N and Nardin G 1981 Inorg. Chim. Acta 54 L17

20. Baggio R, Garland M T, Manzur J, Pena O, Perec M, Spodine E and Vega A 1999 Inorg. Chim. Acta 28674

21. Alarcón-Payera C, Pivettab T, Choquesillo-Lazartea D, González-Péreza J M, Crisponi G, Castiñeirasc A and Niclós-Gutiérrez J 2005 Inorg. Chim. Acta 3581918

22. Bonomo R P, Rizzarelli E, Bresciani Pahor N and Nardin G 1982 J. Chem. Soc., Dalton Trans. 681

23. Nagel J F, Parodi L A and Lozier R H 1982 J. Biophys. 38161

24. Schwetlick K 1975 In Kinetic methods for study of the mechanism of reaction. J Kirejczyk (ed.) (Warsaw: PWN) p. 142

25. Norberg S, Svensson G and Albertsson J 1999 Acta Crystallogr. C 55356

26. Hänggi P, Talkner P and Borkovec M 1990 Rev. Mod. Phys. 62251

27. Eyring H 1935 Chem. Rev. 1765

28. Wyrzykowski D, Pranczk J, Jacewicz D, Tesmar A, Pilarski B and Chmurzyński L 2014 Cent. Eur. J. Chem. 12107 